\title{
Broadband Compact Antenna for S-Band and C-Band Application
}

\author{
Rihana Parveen \\ PG Scholar's \\ SISTECH Bhopal
}

\author{
Mohd Abdulla \\ Asso. Prof \\ SISTECH Bhopal
}

\begin{abstract}
In this paper has designed Compact Dual band antenna for SC Band wireless communication, Meta material and Orthogonal shorting pin techniques are used for the designing of the proposed antenna. Invert U-Slot, Square Slots designed in the patch and Meander slot designed in the ground plan. Slotting has been done using impedance matching and Meta material theory. This work is carried out to design circular polarizated antenna, circular polarization of antenna validated by axial-ratio curve. For achieving compactness shorting pins have loaded in to patch in orthogonal pattern, because of shorting pins the minimum point of lower frequency moves to higher frequency and gives broad AR bandwidth. Microstrip Antenna is a strip antenna which is designed in very small size. it is versatile used in recent communication due to low weight, low profile, flexible in fabrication,. It will be use in GSM, Bluetooth, Radar and satellite application. All application requires compact and broadband antenna. Microstrip Antenna is used in various band in wireless communication application like S- band,C -band.
\end{abstract}

\section{Keywords}

Broadband antenna application, S-Band, C-Band, Orthogonal shorting pin techniques, slotting techniques, Meta material

\section{INTRODUCTION}

HIGH mobility necessity and multiple frequency demands for wireless communication devices increase the interest for compact, low-profile, and multiband antennas in recent years. The frequency ranges of $5.15-5.35$ and $5.725-5.825 \mathrm{GHz}$ in the US and 5.15-5.35 and 5.470-5.725 GHz in Europe are used for wireless local area network (WLAN) that offers data rate up to $54 \mathrm{Mb} / \mathrm{s}$. Different techniques for design of dualband WLAN antenna have been reported in [1]-[4]. In [1], Ali et al. proposed a dual-band/wideband packaged antenna for IEEE 802.11a WLAN band (5.15-5.35 and 5.725-5.825 GHz) application. However, the design compactness was reduced with the dimension of the antenna (28 $93 \mathrm{~mm}$ ) and printed circuit board (PCB) size (120 $802 \mathrm{~mm}$ ). Different techniques for WLAN dual-band designs are reported in [2]-[4]. However, these microstrip antennas are not specifically designed for WLAN 802.11a dual band in which two operating band centers are separated by only $500-550 \mathrm{MHz}$ Therefore, one of the design considerations is to satisfy the required impedance bandwidth necessary for the WLAN dualband application along with maintaining the proper separation frequency gap between them. In [5], Deshmukh et al. presented a bandwidth enhancement technique of microstrip antenna using quarter-wavelength resonant slots. Impedance bandwidths of an S-shaped multiband microstrip antenna [6] and an E-shaped single-band microstrip antenna [7] are enhanced about $\%$ and $24 \%$, respectively, using open-ended rectangular slots. Compact and broadband design methods of low-profile microstrip antennas have been discussed in [8].

\section{DESIGNING OF PROPOSED PATCH ANTENNA}

For designing of any Microstrip patch antenna there are following steps:

- Mathematical Analysis:

1. Selection of substrate for designing of MSA .

2. For numerical analysis there are different type of modals, here transmission line model is used.

3. For providing input to antenna different feeding methods are used. Coaxial feeding technique is used here.

- Antenna design by using simulator software: For simulation of antenna geometry different software are available. IE3D software is used here

Dual band circularly Polarized antenna is discussed. For designing of proposed antenna firstly study and design then loading shorting pin and Meta material for optimization of inductance of design antenna. Shorting pin technique improves the conductivity of ground plan and patch so that reduction in reflection of patches and ground plan. technique enhance surface current of antenna, reduce cross polarization and improve efficiency of proposed antenna, due to improvement in surface current obtain shift in higher edge of frequencies towards lower edge of frequency, Compactness and multiband are achieved by appropriate choosing the dimension of U-Slot. Folded U-Slot has designed using theory of impedance stub matching technique. Proposed antenna design in IE3D Simulator and all results validated in IE3D Simulator. Return losses, VSWR, axial ratio, antenna and radiating efficiency, directivity and radiation pattern discuss in below section.

\subsection{Basic Design}

In fig1, shown proposed Antenna-1, the dimension of proposed antenna is calculated using transmission line theory Dimensions are

- $\quad$ Length and width of patch are

- $\mathrm{L}=17.77 \mathrm{~mm}, \mathrm{~W}=22 \mathrm{~mm}$

- $\quad$ Length and width of ground plan are

$\mathrm{L}_{\mathrm{R}}=26.77 \mathrm{~mm}, \mathrm{~W}_{\mathrm{R}}=31 \mathrm{~mm}$

$\mathrm{L}_{\mathrm{R}}=\mathrm{L}+6 \mathrm{~h}, \mathrm{~W}_{\mathrm{R}}=\mathrm{W}+6 \mathrm{~h}$

Feeding points calculated as

$$
X_{\mathrm{f}}=-4 \mathrm{~mm}, \mathrm{Y}_{\mathrm{f}}=-11 \mathrm{~mm}
$$

The dimensions of U-Slot and square Slot has been calculated using impedance matching theory 


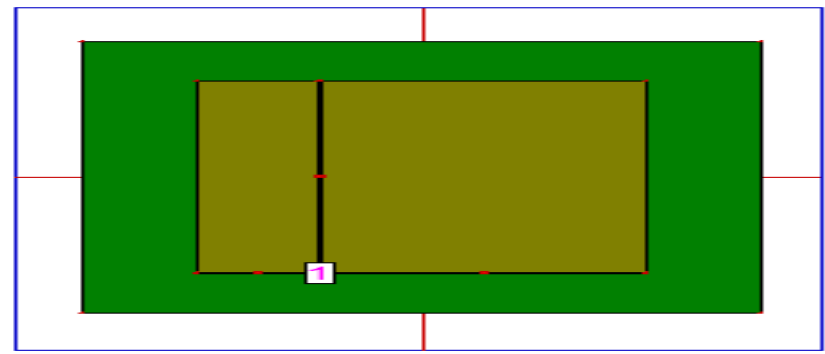

Figure 1 Basic Design

\subsection{Proposed design}

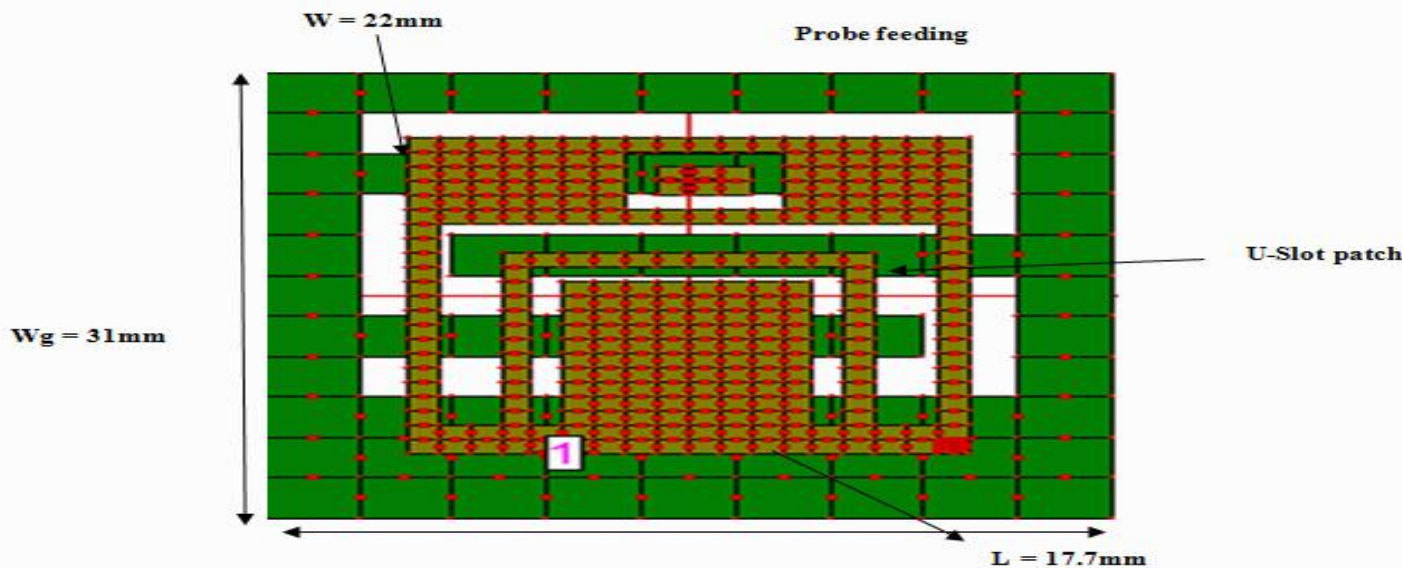

Figure 2 Proposed Design

The ease of insetting and low radiations is advantages of probe feeding as compared to Micro-strip line feeding.
The dimensions of shapes patch shown in above Fig. 2 are designed at operating frequency $5.5 \mathrm{GHz}$.

\section{RESULTS \& DISCUSSION}

\subsection{Return Loss vs. Frequency Graph and Bandwidth}

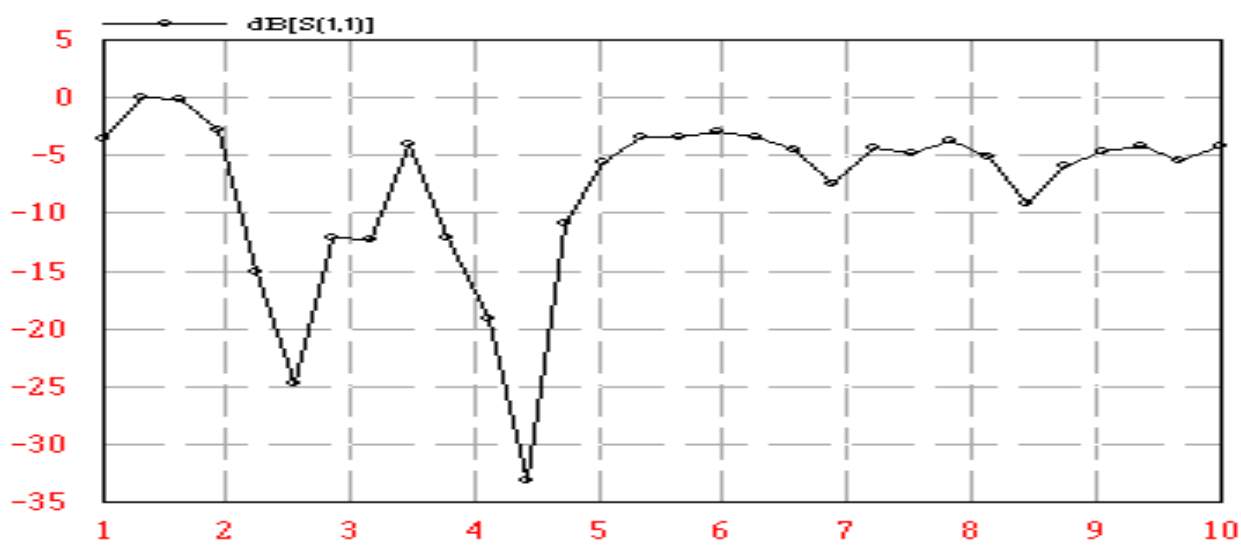

Figure 3 Return loss vs. Frequenc

Return Loss vs. Frequency and Bandwidth is shown in figure 3 Return loss, as stated before, represents the amount of power which is reflected back to the source due to the impedance mismatching. It is calculated in $\mathrm{dB}$. The acceptable value is $-10 \mathrm{~dB}$.Return loss vs. Frequency result is shown in figure 3. Applicable only for three bands. The dimensions of shapes patch shown in Fig 3 .These are designed at operating frequency $6 \mathrm{GHz}$. We achieved Impedance bandwidth S11 $\leq$ $10 \mathrm{~dB}$ is $25 \%$ of $\mathrm{S}$-band, $41 \%$ of $\mathrm{C}$-Band. At $2.55 \mathrm{GHz}$ return losses is $-25 \mathrm{~dB}$ and at $4.4 \mathrm{GHz}$ return loss is $-232 \mathrm{~dB}$. 


\subsection{Axial Ratio vs. Frequency}

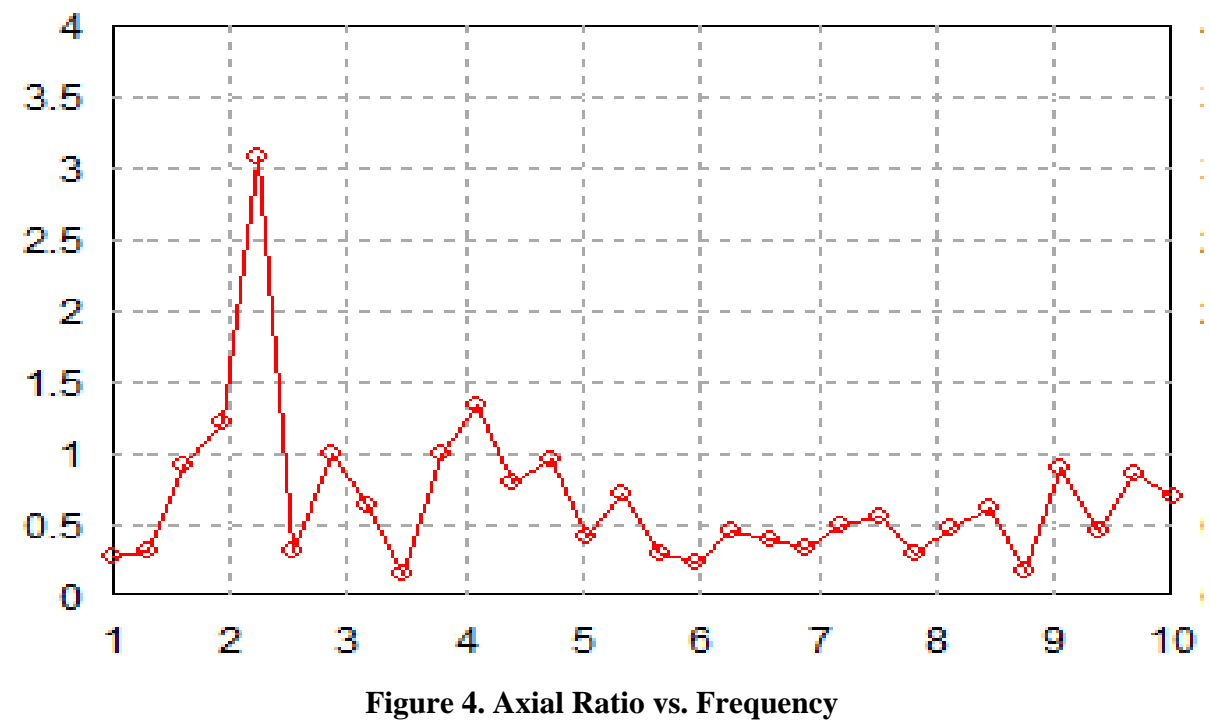

The ease of insetting and low radiations is advantages of probe feeding as compared to Micro-strip line feeding.
The dimensions of shapes patch shown in above Fig. 4.4 are designed at operating frequency $5.5 \mathrm{GH}$

\subsection{Antenna and Radiating Efficiency vs. Frequency}

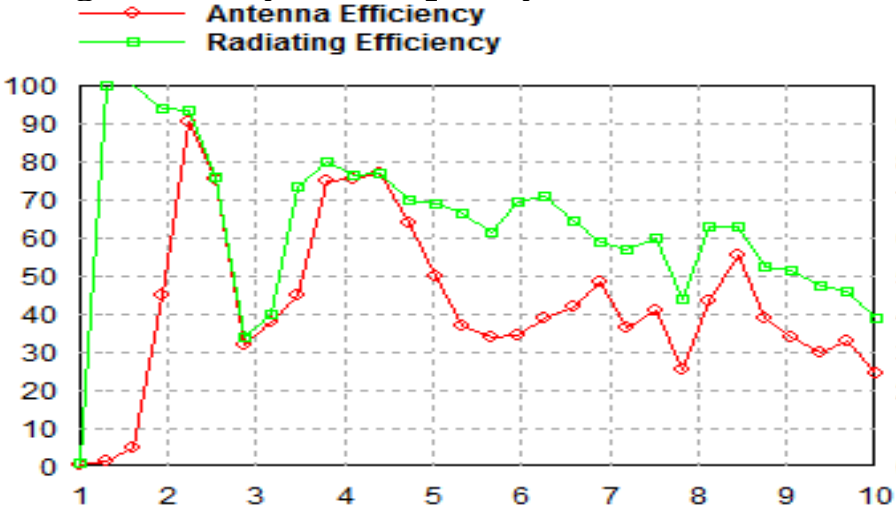

Figure 5. Antenna and Radiating Efficiency vs. Frequency

Antenna and Radiating Efficiency vs. Frequency is shown in figure 5, achieved Antenna efficiency up to $90 \%$ and radiating efficiency $92 \% .2 .55 \mathrm{GHz}$ and $4.4 \mathrm{GHz}$ frequency for different values of $\theta$ and $\varphi$.

\subsection{Radiation Pattern}

The elevation and azimuth patterns have analyzed at two frequency $2.55 \mathrm{GHz}$ and $4.4 \mathrm{GHz}$, the radiation pattern analysis discuss in below section

\subsubsection{Elevation Pattern at $2.55 \mathrm{GHz}$}

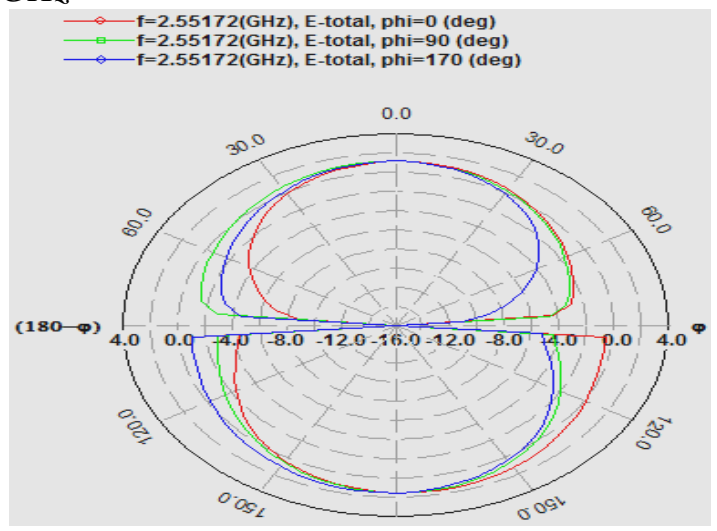

Figure 6 Elevation Pattern at $2.55 \mathrm{GHz}$ 
The radiation pattern is at $2.55 \mathrm{GHz}$ in Maximum gain obtained at 0 and 180 degrees. $3 \mathrm{~dB}$ Beam Width of the radiation pattern is 71.92 degrees

\subsubsection{Elevation Pattern at $4.4 \mathrm{GHz}$}

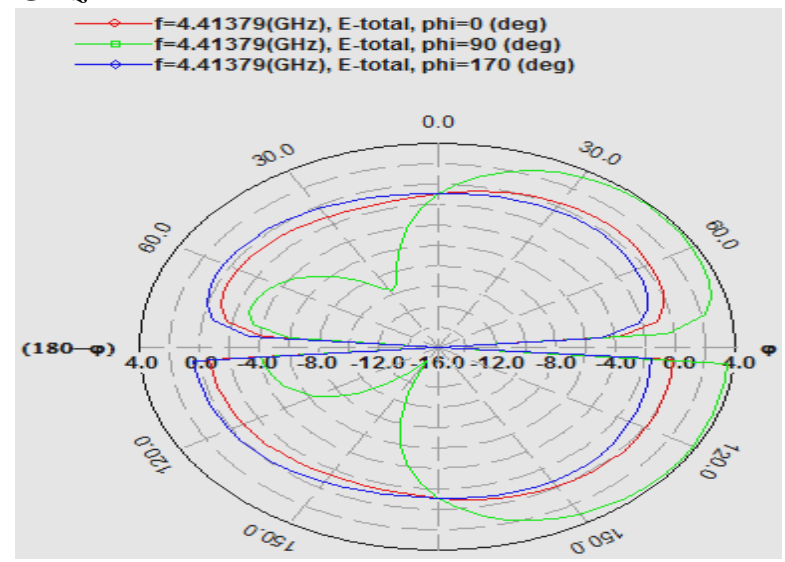

Figure 7. Elevation Pattern at $4.4 \mathrm{GHz}$

3.4.3 Azimuth Pattern at $2.55 \mathrm{GHz}$

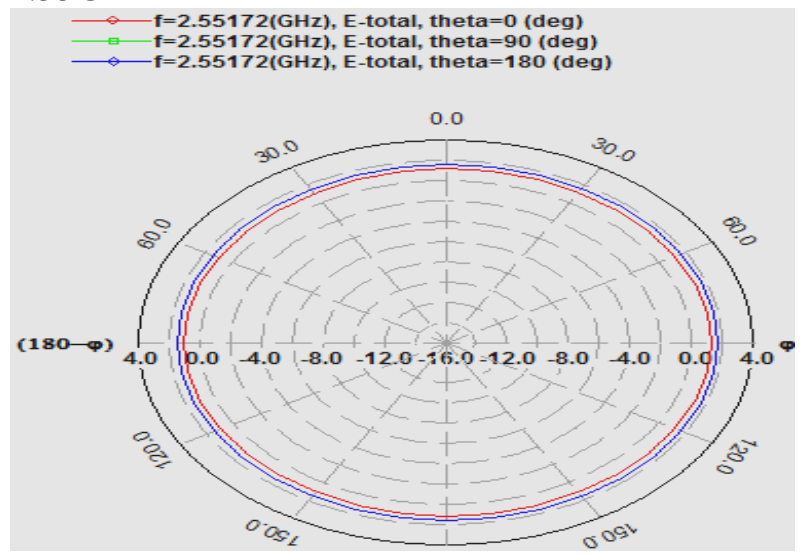

Figure 8 Azimuth Pattern at $2.55 \mathrm{GHz}$

The Azimuth radiation pattern is at $2.55 \mathrm{GHz}$ in radiation pattern only one side lobe occurs. Maximum gain obtained at is -2.31238 degrees. 90 and 270degrees. 3dB Beam Width of the radiation pattern

\section{VALIDATION OF WORK}

Table 1 Validation of Work

\begin{tabular}{|c|c|c|c|}
\hline YEAR & 2015 & 2014 & This Work \\
\hline $\begin{array}{l}\text { PUBLICAT } \\
\text { ION }\end{array}$ & IEEE & IEEE & \\
\hline $\begin{array}{l}\text { Technique } \\
\text { Used }\end{array}$ & $\begin{array}{l}\text { Circularly Polarized } \\
\text { Beam-Scanning } \\
\text { Microstrip } \\
\text { Antenna Using a } \\
\text { Reconfigurable } \\
\text { Parasitic Patch } \\
\text { of Tunable Electrical } \\
\text { Size }\end{array}$ & $\begin{array}{l}\text { Compact Dual-Band } \\
\text { Microstrip Antenna } \\
\text { for } \\
\text { IEEE 802.11a WLAN } \\
\quad \text { Application }\end{array}$ & $\begin{array}{l}\text { - Meander type slotting in ground } \\
\text { plane, } \\
\text { - Invert U-Slot and square slot using } \\
\text { meta material } \\
\text { - Orthogonal shorting pins }\end{array}$ \\
\hline $\begin{array}{c}\text { RES. } \\
\text { FREQ. }\end{array}$ & $\begin{array}{l}2.4-2.5 \mathrm{GHz}, 1.2 \\
\mathrm{GHz} \text { and } 1.7 \mathrm{GHz}\end{array}$ & $\begin{array}{c}5.15-5.35 \text { and } 5.725- \\
5.825 \mathrm{GHz}\end{array}$ & $2.5 \mathrm{GHz}, 4.5 \mathrm{GHz}$ \\
\hline
\end{tabular}




\begin{tabular}{|c|c|c|c|}
\hline $\begin{array}{c}\text { FEEDING } \\
\text { METHOD }\end{array}$ & Coaxial probe feed & Coaxial probe feed & Coaxial probe feed \\
\hline $\begin{array}{c}\text { Impedance } \\
\text { bandwidth }\end{array}$ & $2 \%$, & $4 \%, 1.7 \%$ & $41 \%, 25 \%$ \\
\hline $\begin{array}{c}\text { Axial Ratio } \\
\text { bandwidth } \\
\text { 3dB }\end{array}$ & $2.38-2.63 \mathrm{GHz}$ & $2.1 \mathrm{GHz}$ to $4.8 \mathrm{GHz}$ \\
\hline
\end{tabular}

Table 1 compares the proposed work with existing techniques, after comparision concludes that this research work provides Compactness and Triple band like S-Band, C-Band from single geometry.

\section{CONCLUSION}

Compact dual band antenna for S-C Band wireless communication is successfully investigated by one U-Slot, one Square slot with two orthogonal shorting pin, achieved $10 \mathrm{~dB}$, Impedance bandwidth $41 \%$ from $2.1 \mathrm{GHz}$ to $3.2 \mathrm{GHz}$ for S-Band.-10dB, Impedance bandwidth $25 \%$ from $3.7 \mathrm{GHz}$ to $4.8 \mathrm{GHz}$ for C-Band. Achieved compactness $48 \%$ at $2.55 \mathrm{GHz}$, $20 \%$ at $4 \mathrm{GHz}$. At $2.55 \mathrm{GHz}$ return losses is $-25 \mathrm{~dB}$ and at 4.4 $\mathrm{GHz}$ return loss is $-32 \mathrm{~dB}$. IE3DTM Simulator used for validation of proposed antenna. Meta material and orthogonal shorting pin techniques are used. Slotting has been done using impedance matching and meta material Invert U-Slot, Square Slot in the patch and Meander slot designed in the ground plan Circular polarization of antenna validated by axial-ratio (AR) curve. For achieving compactness and By loading a shorting pins to the patch in orthogonal pattern, the minimum point of lower frequency moves to higher frequency, and broad AR band is obtained consequently Compact dual band antenna for S-C Band is presented using The measured parameters satisfy required limits hence making the proposed antenna suitable for S-C Band applications, GSM, Satellite and radar application

\section{REFERENCES}

[1] T. Sittironnarit, H. S. Hwang, R. A. Sadler, and G. J. Hayes, "Wide band/dual band packaged antenna for 5-6 $\mathrm{GHz}$ WLAN application," IEEE Trans. Antennas Propag., vol. 52, no. 2, pp. 610-615, Feb. 2004.

[2] L. Li, S.W. Cheung, and T. I. Yuk, "Dual band antenna with compact radiator for 2.4/5.2/5.8 GHz WLAN applications," IEEE Trans. Antennas Propag., vol. 60, no. 12, pp. 5924-5931, Dec. 2012.

[3] A. Khaleghi, "Dual band meander line antenna for wireless LAN communication," IEEE Trans. Antennas Propag., vol. 55, no. 3, pp.1404-1409, Mar. 2007.

[4] C.-Y. Huang and E.-Z. Yu, "A slot-monopole antenna for dual-band WLAN applications," IEEE Antennas Wireless Propag. Lett., vol. 10,pp. 500-502, 2011.

[5] A. A. Deshmukh and K. P. Ray, "Compact broadband slotted rectangular microstrip antenna," IEEE Antennas Wireless Propag. Lett., vol.8, pp. 1410-1413, 2009.

[6] J. M. Patel, S. K. Patel, and F. N. Thakkar, "Comparative analysis of S-shaped multiband microstrip patch antenna," Int. J. Adv. Res. Elect. Electron. Instrum. Eng., vol. 2, no. 7, pp. 3273-3280, 2013.
[7] K.-L. Wong and W.-H. Hsu, "A broad-band rectangular patch antenna with a pair of wide slits," IEEE Trans. Antennas Propag., vol. 49, no.9, pp. 1345-1347, Sep. 2001.

[8] K. L. Wong, Compact and Broadband Microstrip Antennas. New York, NY, USA: Wiley, 2002.

[9] U. Chakraborty, S. K. Chowdhury, and A. K.

[10] Bhatacharjee, "Frequency tuning andminiaturization of squaremicrostrip antenna embedded with ' $T$ '-shaped defected ground structure," Microw. Opt. Technol. Lett.vol. 55, no. 4, pp. 869-872, Apr. 2013.

[11] Juhua Liu, QuanXue, et.al,’Design and Analysis of a Low-Profile and Broadband MicrostripMonopolar Patch Antenna" IEEE Transactions on Antennas and Propagation, Vol. 61, No. 1, January 2013.

[12] Ying Liu.et.al,A Novel Miniaturized Broadband DualPolarized Dipole Antenna for Base Station" IEEE Antennas And Wireless Propagation Letters, Vol. 12, 20131335.

[13] Olivier Clauzier.et.al,"Compact Dual-Linear Polarized Wideband Antenna for VHF/UHF Band” IEEE Antennas and Wireless Propagation Letters, Vol. 12, 2013.

[14] TingqiangWu.et.al, "A Compact And Broadband Microstrip Stacked Patch Antenna With Circular Polarization For 2.45-Ghz Mobile RFID Reader "IEEE Antennas And Wireless Propagation Letters, Vol. 12, 2013 .

[15] Ahmed Khidre.et.al, "Wide Band Dual-Beam U-Slot Microstrip Antenna" IEEE Transactions on Antennas and Propagation, Vol. 61, NO.3, March 20131415.

[16] U. Chakraborty.et.al, "Compact Dual-Band Microstrip Antenna for IEEE 802.11a WLAN Application" IEEE Antennas And Wireless Propagation Letters, Vol. 13, 2014407.

[17] Chawanonphithak. et.al, "Compact dual-band I-shaped patch antenna with longitudinal strip on inverted-T ground plane " Information and Communication Technology, Electronic and Electrical Engineering (JICTEE), 2014 4th IEEE, Page(s): 1 - 4.

[18] Kachare,Rupali.et.al, “Compact dual band planar monopole antenna for WLAN/WiMAX “ Communications and Signal Processing (ICCSP), 2014 IEEE Conference 2014, Page(s): 391 - 394. 